Article

\title{
Antioxidant Effect via Bioconversion of Isoflavonoid in Astragalus membranaceus Fermented by Lactiplantibacillus plantarum MG5276 In Vitro and In Vivo
}

\author{
Ji Yeon Lee $\mathbb{(})$, Hye Min Park (1) and Chang-Ho Kang *(1)
}

Citation: Lee, J.Y.; Park, H.M.; Kang, C.-H. Antioxidant Effect via Bioconversion of Isoflavonoid in Astragalus membranaceus Fermented by Lactiplantibacillus plantarum MG5276 In Vitro and In Vivo. Fermentation 2022, 8, 34. https:// doi.org/10.3390/fermentation8010034

Academic Editor: Hiroshi Kitagaki

Received: 26 November 2021

Accepted: 13 January 2022

Published: 16 January 2022

Publisher's Note: MDPI stays neutral with regard to jurisdictional claims in published maps and institutional affiliations.

Copyright: (c) 2022 by the authors. Licensee MDPI, Basel, Switzerland. This article is an open access article distributed under the terms and conditions of the Creative Commons Attribution (CC BY) license (https:// creativecommons.org/licenses/by/ $4.0 /)$.
MEDIOGEN, Co., Ltd., Biovalley 1-ro, Jecheon-si 27159, Korea; ljy341@naver.com (J.Y.L.); hyeminpark95@naver.com (H.M.P.)

* Correspondence: changho-kang@naver.com; Tel.: +82-43-842-1940

\begin{abstract}
In this study, the antioxidant mechanism of Astragalus membranaceus fermented by Lactiplantibacillus plantarum MG5276 (MG5276F-AM) was evaluated in HepG2 cells and in an animal model. HPLC analysis was performed to confirm the bioconversion of the bioactive compounds in A. membranaceus by fermentation. Calycosin and formononetin, which were not detected before fermentation (NF-AM), were detected after fermentation (MG5276F-AM), and its glycoside was not observed in MG5276F-AM. In HepG2 cells, MG5276F-AM alleviated $\mathrm{H}_{2} \mathrm{O}_{2}$-induced oxidative stress by mediating lipid peroxidation and glutathione levels, and upregulated antioxidant enzymes including catalase (CAT), superoxide dismutase (SOD), and glutathione peroxidase (GPx). In the tBHP-injected mouse model, administration of MG5276F-AM reduced hepatic aspartate transaminase, alanine transaminase, and lipid peroxidation. MG5276F-AM also modulated antioxidant enzymes as well as HepG2 cells. Thus, fermentation of A. membranaceus with L. plantarum MG5276 elevated the isoflavonoid aglycone by hydrolysis of its glycosides, and this bioconversion enhanced antioxidant activity both in vitro and in vivo.
\end{abstract}

Keywords: antioxidant; formononetin; calycosin; HepG2 cells; t-BHP

\section{Introduction}

Antioxidants prevent oxidative stress produced by a variety of environmental conditions, including alcohol consumption, smoking, and drug addiction [1]. Chronic oxidative stress is caused by the accumulation of reactive oxygen species (ROS), including hydrogen peroxide $\left(\mathrm{H}_{2} \mathrm{O}_{2}\right)$, hydroxyl radicals $\left(\mathrm{OH}^{-}\right)$, and free radicals $\left(\mathrm{O}^{-}\right)$in organelles. ROS induce cancer, aging, and inflammation by causing cell membrane degradation, lipid oxidation, protein denaturation, and DNA damage [2]. To protect against oxidative stress, organelles have enzymatic and non-enzymatic antioxidant defense systems [3]. Oxidative stress accumulated in cells is relieved by antioxidant enzymes such as SOD, CAT, and GPx. Free radicals are converted to $\mathrm{H}_{2} \mathrm{O}_{2}$ by SOD and degraded to $\mathrm{H}_{2} \mathrm{O}$ by CAT and/or GPx to relieve oxidative stress [4]. What is more, non-enzymatic defense system against oxidative stress involves flavonoids such as flavanoid, flavonols, isoflavonoids, and phenolic acid, which are abundant in foods, plants and beverages [5]. The balance between the activity and intracellular levels of antioxidants is important for human health [4].

Bioconversion is the conversion of organic materials from natural product by biological processes [6]. In the food industry, bioconversion is used to produce feed and energy using food waste, and to improve bioactivity and bioavailability $[7,8]$. In particular, lactic acid bacteria, which are probiotics, are widely used in the functional food industry [9]. Among the lactic acid bacteria used for bioconversion, Lactiplantibacillus plantarum has been used to convert flavonoid glycosides in Cudrania tricuspidata leaves into its aglycone, and to convert ginsenoside $\mathrm{Rb} 2$ and $\mathrm{Rb} 3$ in red ginseng to ginsenoside $\mathrm{Rd}[10,11]$. It has also been 
reported that immune system regulation, whitening, and antioxidant activity of various natural products are enhanced through bioconversion using L. plantarum [6,12].

Roots of Astragalus membranaceus (A. membranaceus) have been grown in Korea, China, and Mongolia [13]. A. membranaceus has been used traditionally for the treatment of cancer, hyperglycemia, and immune modulating-related diseases, and contains mainly polysaccharides, astragaloside, and various flavonoids [14]. In a previous study, A. membranaceus fermented by L. plantarum MG5276 (MG5276F-AM) had antioxidant and anti-inflammatory effects through decreasing nitro oxide (NO) production and gene expression of inducible nitric oxide synthase (iNOS) and cyclooxygenase-2 (COX-2) in RAW264.7 cells [15]. As a further study, the bioconversion of isoflavonoid glycosides calycosin-7-O-glucoside and formononetin-7-O-glucoside in $A$. membranaceus by fermentation was confirmed through HPLC analysis, and the antioxidant efficacy of MG5276F-AM was verified in cells and animal models.

\section{Materials and Methods}

\subsection{Preparation and Fermentation of Astragalus Membranaceus Extract}

The fermentation method was performed as previously described [15]. Briefly, L. plantarum MG5276, isolated from fermented foods, was cultured in ManRogosaSharpe (MRS; Difco, Sparks, MD, USA) broth at $37^{\circ} \mathrm{C}$ for $24 \mathrm{~h}$. The roots of $A$. membranaceus were purchased from the Chungbuk Herb Farming Association (Jecheon, Korea). A. membranaceus (100 g) was extracted in hot water $\left(w: v=1: 2,60{ }^{\circ} \mathrm{C}\right)$ for $15 \mathrm{~h}$. The $A$. membranaceus extract was filtered using Whatman No. 2 filter paper (GE Healthcare Bio-Science, PA, USA). Then, 2\% (v/v) of L. plantarum MG5276 $\left(\mathrm{OD}_{600}=1.0,10^{8}-10^{9} \mathrm{CFU} / \mathrm{mL}\right)$ was inoculated and fermented for A. membranaceus extract at $37^{\circ} \mathrm{C}$ for $15 \mathrm{~h}$. After fermentation, the supernatant was filtered and freeze-dried for subsequent experiments.

\subsection{High Perfomance Liquid Chromatography (HPLC) Analysis}

\subsubsection{Pre-treatment of Samples for Analysis}

Previously study reported that isoflavonoids from AM was contained in ethyl acetate fraction [16,17]. Therefore, the isoflavonoid-rich sample for HPLC analysis was conducted by ethyl acetate fraction. NF-AM and MG5276F-AM ( $1 \mathrm{~g}$, each) were dissolved in water then fractionated with ethyl acetate. Fractions of each sample were dissolved in methanol (50 mg/mL each) following concentration under reduced pressure.

\subsubsection{Analysis of Isoflavonoids by HPLC}

For qualitative and quantitative analysis of isoflavonoids, HPLC (Shimadzu, Kyoto, Japan) was performed using a reverse-phase system. Calycosin, formononetin, calycosin7-O-glucoside (calycosin-G), and formononetin-7-O-glucoside (formononetin-G), used as a standard, were from Sigma-Aldrich (St. Louis, MO, USA). A Kinetex EVO C18 $(4.6 \times 250 \mathrm{~mm}, 5 \mu \mathrm{m}$; Phenomenex, Torrance, CA, USA) column was used with a mobile phase consisting of $0.1 \%$ acetic acid in water $(\mathrm{A}, v / v)$ and $0.1 \%$ acetic acid in acetonitrile $(\mathrm{B}, v / v)$. The injection volume was $10 \mu \mathrm{L}$, the flow rate was $1.0 \mathrm{~mL} / \mathrm{min}$, and UV detection was conducted at $260 \mathrm{~nm}$. The elution program was modified from Park's program [13]. The elution program was as follows (B\%): 10-15\%, $10 \mathrm{~min} ; 15-20 \%, 15 \mathrm{~min} ; 20-30 \%, 25 \mathrm{~min}$; 30-40\%, $45 \mathrm{~min} ; 40-100 \%$, $55 \mathrm{~min} ; 100 \%$, $65 \mathrm{~min}$.

\subsection{Cell Culture}

HepG2 cells were obtained from the KTCC (Seoul, Korea). HepG2 cells were cultured in minimum essential medium (MEM) supplemented with $10 \%$ fetal bovine serum (FBS) and $1 \%$ penicillin-streptomycin (Gibco BRL, Burlington, $\mathrm{ON}$, Canada) at $37^{\circ} \mathrm{C}$ in a $5 \% \mathrm{CO}_{2}$ incubator. The medium was replaced every 2 days for subculture. 


\subsection{Cell Viability}

Cell viability was measured using the 3-(4,5-Dimethylthiazol-2-yl)-2,5-Diphenyltetrazolium bromide (MTT) assay [18]. Briefly, cells $\left(4 \times 10^{4}\right.$ cells/well) were seeded in 96 well plates incubated at $37^{\circ} \mathrm{C}$ in $5 \% \mathrm{CO}_{2}$ for $24 \mathrm{~h}$. After aspirating the supernatant, $100 \mu \mathrm{L}$ of NF-AM and MG5276F-AM (25 and $50 \mu \mathrm{g} / \mathrm{mL}$ in serum free MEM) was treated in each well. After $24 \mathrm{~h}, \mathrm{H}_{2} \mathrm{O}_{2}(1 \mathrm{mM})$ with samples was added to the each well for $24 \mathrm{~h}$. After aspirating the supernatant, $100 \mu \mathrm{L}$ of MTT solution $(0.1 \mathrm{mg} / \mathrm{mL}$ in serum free MEM) was added to each well, incubated for $2 \mathrm{~h}$. Formazan produced by MTT solution was dissolved by DMSO $(150 \mu \mathrm{L})$ and absorbance at $550 \mathrm{~nm}$ was measured using an Epoch2 microplate reader (Biotek, Winooski, VT, USA).

\subsection{Quantitative Real-Time Polymerase Chain Reaction ( $q R T-P C R$ )}

Total RNA was isolated from hepatocytes using NuceloZOL (MACHEREY-NAGEL GmbH \& Co., KG, Dueren, Germany), and mRNA (1 $\mu$ g) was reverse-transcribed into cDNA using Reverse Transcriptase Premix (Intron, Seongnam-si, Korea). qRT-PCR was performed using $\mathrm{iQ}^{\mathrm{TM}} \mathrm{SYBR}{ }^{\circledR}$ Green Supermix (Bio-Rad, Hercules, CA, USA) with the gene primers listed in Table 1. Relative gene expression was normalized to glyceraldehyde 3-phosphate dehydrogenase (GAPDH). Expression levels were analyzed using the $2^{-\Delta \Delta C T}$ method [19].

Table 1. Primer sequences for qRT-PCR.

\begin{tabular}{cccc}
\hline Gene $^{\mathbf{1}}$ & & Primer Sequence $^{\left(\mathbf{5}^{\prime} \rightarrow \mathbf{3}^{\prime}\right)}$ & Product Size (bp) \\
\hline CAT & Forward & GAACTGTCCCTACCGTGCTCGA & 156 \\
& Reverse & CCAGAATATTGGATGCTGTGCTCCAGG & 186 \\
SOD & Forward & AATGGACCAGTGAAGGTGTGGGG & 122 \\
& Reverse & CACATTGCCCAAGTCTCCAACATGC & 178 \\
GPX & Forward & CGGCCCAGTCGGTGTATGC & \\
& Reverse & CGTGGTGCCTCAGAGGGAC & \multirow{2}{*}{ FAPDH } \\
& Forward & ACCCACTCCTCCACCTTTG & \\
& Reverse & CTCTTGTGCTCTTGCTGGG & \\
\hline
\end{tabular}

${ }^{1}$ qRT-PCR, quantitative real-time polymerase chain reaction; $C A T$, catalase; $S O D$, superoxide dismutase; $G P X$, glutathione peroxide; GAPDH, glyceraldehyde 3-phosphate dehydrogenase.

\subsection{Animal Treatments}

All animal experimental protocols used in this study were approved by the Institutional Animal Care and Use Committee (IACUC) of the Korea Institute of NDIC (P214057, Seoul, Korea, 21 October 2021). Five-week-old female C57BL/6 mice were used in this study (Orient Bio., Seongnam-si, Korea). The mice were housed in standard polycarbonate cages ( $n=4-5$ per cage) at a controlled temperature of $21 \pm 2{ }^{\circ} \mathrm{C}$ and humidity of $50 \pm 20 \%$ under a 12-h light/dark cycle and given free access to standard rodent chow (Research Diets, Inc., New Brunswick, NJ, USA) and water. All solutions used for the treatments were freshly dissolved on the experimental days in physiological saline (Dai Han Pharm. Co., Ltd., Seoul, Korea).

After a week of acclimatization, the mice were randomly divided into four groups ( $n=7$ per group) as follows: (1) normal group (saline), (2) tert-butyl hydroperoxide ( $t$-BHP) in saline-injected group, (3) $t$-BHP + MG5276F-AM (100 mg/kg), and (4) $t$-BHP + MG5276F$\mathrm{AM}(300 \mathrm{mg} / \mathrm{kg})$. The extracts were administered orally for 14 days with a feeding needle catheter, and the mice received an intraperitoneal (i.p.) injection of $t$-BHP $(0.5 \mathrm{mmol} / \mathrm{kg})$ after $3 \mathrm{~h}$ from the last feed [20]. Following euthanasia, the liver tissues were dissected and stored at $-80^{\circ} \mathrm{C}$ for biochemical parameter analysis.

\subsection{Biochemical Parameters of Serum and Liver Tissues}

Serum alanine aminotransferase (ALT) and aspartate aminotransferase (AST) levels were evaluated using a chemistry analyzer (AU480, Beckman Coulter, CA, USA). The liver 
tissue was lysed using RIPA buffer (Biosesang, Seongnam-si, Korea) containing protease inhibitor (Gendepot, Katy, TX, USA) and homogenized using TissueLyser II (Qiagen, Hilden, Germany) with stainless steel beads (Qiagen). Malondialdehyde (MDA) (LS Bio, Seattle, DC, USA), glutathione (GSH, Abcam, Cambridge, UK), SOD (Abcam), CAT (Abcam), and GPx (Abcam) were evaluated using ELISA kits. The absorbance was measured using a SpectraMax M2 microplate reader (Molecular Devices, San Jose, CA, USA).

\subsection{Statistical Analysis}

Data are expressed as mean \pm standard error of the mean (SEM) and analyzed by multiple comparisons one-way analysis of variance (ANOVA) using Duncan's multiple range test, IBM SPSS Statistics 21 software program (SPSS Inc., Chicago, IL, USA). The results were considered statistically significant if $\mathrm{p}$ values were less than 0.05 .

\section{Results and Discussion}

\subsection{Analysis Method Vaildation of Isoflavonoids Aglycones and Its Glycosides}

The analytical method used for quantification of calycosin, formononetin, calycosinG, and formononetin-G using HPLC was verified by the limit of detection (LOD) using the slope, and limit of quantification (LOQ) using the standard deviation obtained through linearity (Table 2). The retention times of isoflavonoid aglycones (calycosin and formononetin) and its glycosides (calycosin-G and formononetin-G) were 15.74, 30.36, 64.76, and $44.71 \mathrm{~min}$, respectively. The calibration curves of isoflavonoids and their glycosides were $\mathrm{Y}=57,122 \mathrm{X}-19,253, \mathrm{Y}=46,662 \mathrm{X}-9324, \mathrm{Y}=55,047 \mathrm{X}-22,903$, and $\mathrm{Y}=52,371 \mathrm{X}-22,302$, respectively. In addition, LOD and LOQ were determined to be 1.66, $2.47,2.93$, and $3.43 \mu \mathrm{g} / \mathrm{mL}$ and $5.02,7.49,8.87$, and $10.40 \mu \mathrm{g} / \mathrm{mL}$, respectively.

Table 2. Calibration curves, the LOD and LOQ values of standards for quantification in NF-AM and MG5276F-AM $(n=3)$.

\begin{tabular}{cccccc}
\hline Standards $^{\mathbf{1}}$ & $\begin{array}{c}\text { Rt } \\
(\mathbf{m i n})\end{array}$ & Calibration Curve $^{2}$ & $\mathbf{R}^{2,3}$ & $\begin{array}{c}\text { LOD } \\
(\boldsymbol{\mu} \mathbf{g} / \mathbf{m L})\end{array}$ & $\begin{array}{c}\text { LOQ } \\
(\boldsymbol{\mu} \mathbf{g} / \mathbf{m L})\end{array}$ \\
\hline Calycosin-G & 15.74 & $\mathrm{Y}=57,122 X-19,253$ & 1.00 & 1.66 & 5.02 \\
Formononetin-G & 30.36 & $\mathrm{Y}=46,662 X-9324$ & 1.00 & 2.47 & 7.49 \\
Calycosin & 34.76 & $\mathrm{Y}=55,047 \mathrm{X}-22,903$ & 1.00 & 2.93 & 8.87 \\
Formononetin & 44.71 & $\mathrm{Y}=52,371 \mathrm{X}-22,302$ & 1.00 & 3.43 & 10.40 \\
\hline
\end{tabular}

${ }^{1}$ Calycosin-G, calycosin-7-O-glucoside; Formononetin-G, formononetin-7-O-glucoside. ${ }^{2}$ Where the $\mathrm{Y}$ and $\mathrm{X}$ are the peak area and concentration of the analyses $(\mu \mathrm{g} / \mathrm{mL})$, respectively. ${ }^{3}$ Correlation coefficients for three data points in the calibration curve. Rt, retention time; LOD, limit of detection; LOQ, limit of quantification.

Linearity should be evaluated through the y-intercept and the slope of the regression line with a correlation coefficient of 0.999 or higher after calculating the calibration curve with the analyzed area values [21]. Since the correlation coefficient calculated through the regression curves of all standards was 0.999 or more, it could be quantified using this analysis method.

\subsection{Quantification of Isoflavonoids Aglycones and Its Glycosides Changed through the Fermentation Process of Astragalus membranaceus Extracts}

A. membranaceus extract contains various compounds, including dihydroflavones, isoflavonoids, flavonoids, pterocarpans, phenolic acids, and saponins [14]. Among these compounds, isoflavonoids, such as calycosin and formononetin, are the main components that reduce oxidative stress [22]. In addition, the glycoside in the various extracts can be converted by using the lactobacilli produced through the fermentation process [23]. To confirm the isoflavonoid change in $A$. membranaceus extract through fermentation, it was analyzed using the method described in Section 3.1.

The chromatograms of the isoflavonoid aglycones (calycosin and formononetin) and its glycosides (calycosin-G and formononetin-G) matched with UV spectrum, in NF-AM and MG5276F-AM, are shown in Figure 1. Retention time each isoflavonoid is indicated in 
Table 1. The chromatograms confirmed that the isoflavonoid glycoside that existed before fermentation (Figure 1A) disappeared after fermentation, and isoflavonoid aglycones were generated (Figure 1B).

(A)

mAU

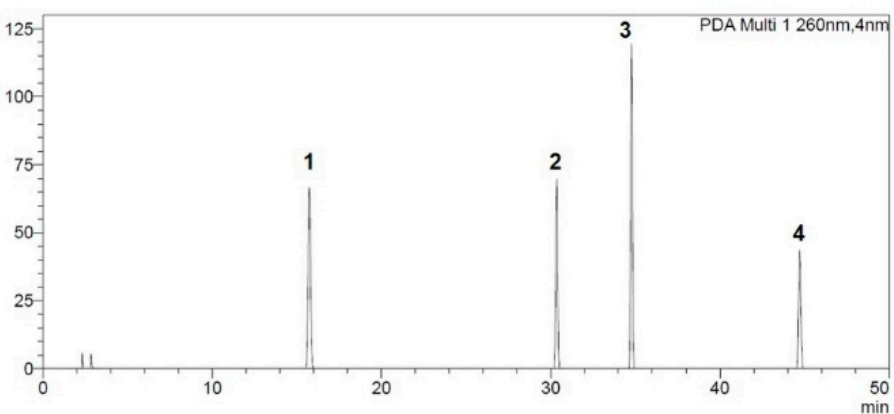

(B)

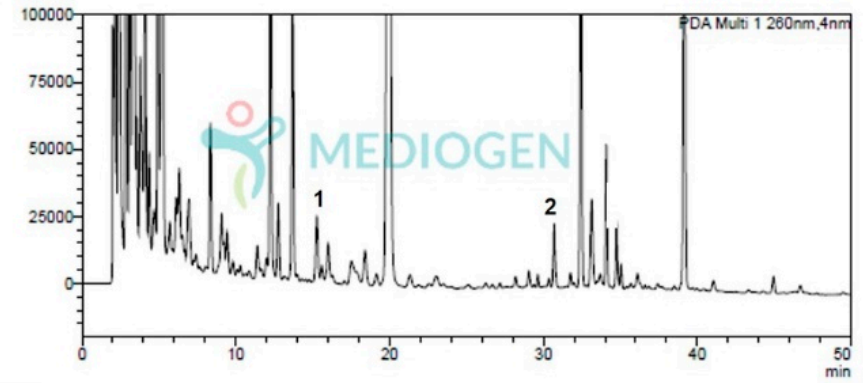

(C)

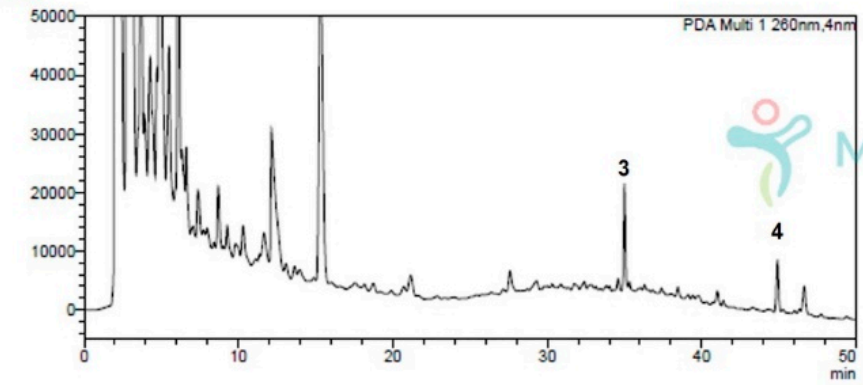

Figure 1. The chromatograms of (A) standards (20 ppm, each), (B) NF-AM (50 mg/mL), and (C) MG5276F-AM (50 mg/mL) by HPLC analysis. 1, calycosin-7-O-glucoside; 2, formonetin-7-Oglucoside; 3, calycosin; 4, formononetin.

The contents of isoflavonoid aglycones and their glycosides are listed in Table 3 . In $\mathrm{NF}-\mathrm{AM}$, only the isoflavonoids glycosides, calycosin-G $(0.91 \pm 0.01 \mathrm{mg} / 100 \mathrm{~g}$ dried weight $)$ and formononetin-G $(0.58 \pm 0.00 \mathrm{mg} / 100 \mathrm{~g}$ dried weight $)$, were analyzed. In MG5276F$\mathrm{AM}$, only isoflavonoids aglycones, calycosin $(0.88 \pm 0.02 \mathrm{mg} / 100 \mathrm{~g}$ dried weight $)$ and formononetin $(0.87 \pm 0.00 \mathrm{mg} / 100 \mathrm{~g}$ dried weight), were analyzed.

Table 3. Contents of isoflavonoids aglycones and its glycosides in NF-AM and MG5276F-AM $(n=3)$.

\begin{tabular}{ccccc}
\hline \multirow{2}{*}{ Sample $^{1}$} & \multicolumn{4}{c}{ Content $(\mathbf{m g} / \mathbf{1 0 0}$ g Dried Weight) } \\
\cline { 2 - 5 } & Calycosin & Formononetin & Calycosin-G & Formononetin-G \\
\hline NF-AM & n.d. ${ }^{2}$ & n.d. & $0.91 \pm 0.01$ & $0.58 \pm 0.00$ \\
MG5276F-AM & $0.88 \pm 0.02$ & $0.87 \pm 0.00$ & n.d. & n.d. \\
\hline
\end{tabular}

${ }^{1}$ Calycosin-G, calycosin-7-O-glucoside; Formononetin-G, formononetin-7-O-glucoside; NF-AM, A. membranaceus, not fermented; MG5276F-AM, A. membranaceus fermented with L. plantarum MG5276. ${ }^{2}$ n.d. not detected. 
L. plantarum contains various enzymes, including phosphohydrolase, $\alpha$-galactosidase, $\alpha$-glucosidase, acid phosphatase, and $\beta$-glucosidase [24]. Calycosin and formononetin are bound to 7-O-glucoside, which can be degraded by the $\beta$-glucosidase produced by L. plantarum [25]. In addition, many studies have been conducted using lactic acid bacteria for the bioconversion of glycosides to aglycones of bioactive compounds [23,26,27]. In our previously study, we only confirmed that calycosin content was increased by MG5276 fermentation [15]. However, in this study, we conducted quantitative and qualitative analyzes of glycosides and other isoflavonoids to determine why the calycosin content was increased. Our results confirmed that glycosides were decomposed to produce aglycones when the A. membranaceus extract was fermented. However, the formononetin content after fermentation was higher than that of formononetin-7-O-glucoside before fermentation. These results show that formononetin is synthesized by other enzymes and compounds other than $\beta$-glucosidase via the biosynthetic pathway [28]. Isoflavonoid glycosides have a very low absorption rate in the body; therefore, a bioconversion process that converts them into an isoflavonoid aglycone is urgently needed to compensate for this [27]. Therefore, conversion to aglycone is important for increasing bioactivity by increasing absorption in the body. Overall, fermentation of $A$. membranaceus extract with L. plantarum MG5276 suggests that bioactivity and bioavailability can be enhanced by increasing the isoflavonoid aglycone.

\subsection{Cytoprotective Effect of NF-AM and MG5276F-AM in $\mathrm{H}_{2} \mathrm{O}_{2}$-Induced HepG2 Cells}

To establish a concentration of NF-AM and MG5276F-AM that is not toxic to cells, viability was measured in HepG2 cells (Figure 2A). Based on these results, only NF-AM and MG5276F-AM at concentrations up to $50 \mu \mathrm{g} / \mathrm{mL}$ were used in subsequent experiments. The cytoprotective effects of NF-AM and MG5276F-AM were investigated in $\mathrm{H}_{2} \mathrm{O}_{2}$-induced HepG2 cells (Figure 2B). Treatment with $\mathrm{H}_{2} \mathrm{O}_{2}(0.1$ to $1 \mathrm{mM})$ on HepG2 cells reduced cell viability in a concentration-dependent manner. Cell morphology and toxicity were observed at a concentration of $1 \mathrm{mM} \mathrm{H}_{2} \mathrm{O}_{2}$ (Figure S1). As a result of treat with NF-AM and MG5276F-AM and $1 \mathrm{mM} \mathrm{H}_{2} \mathrm{O}_{2}$ in HepG2 cells, the viability of MG5276F-AM was significantly higher than that of NF-AM.
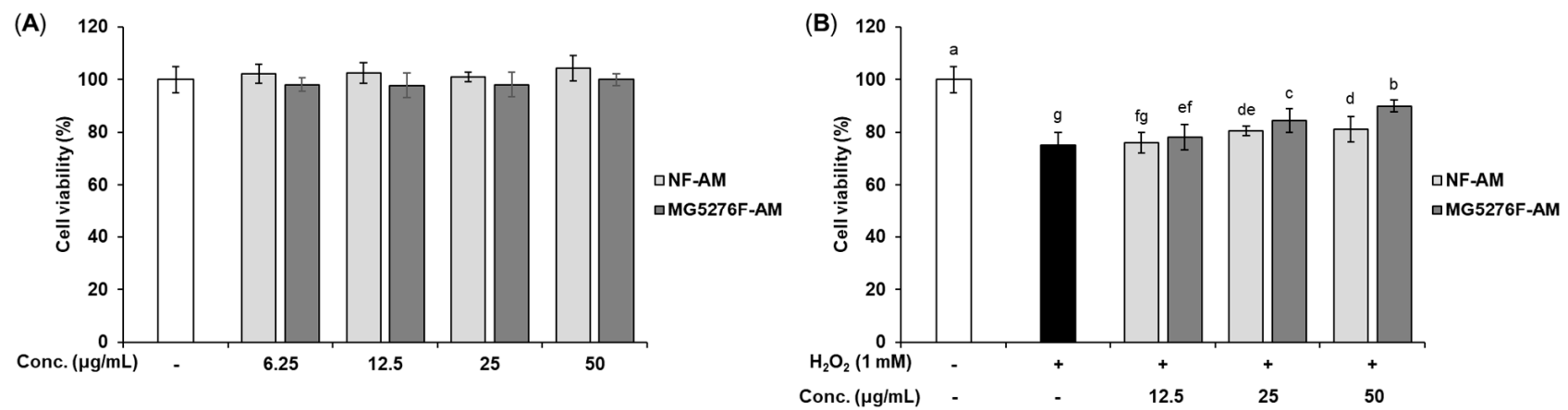

Figure 2. Cell viability of NF-AM and MG5276F-AM on hepatocytes. (A) HepG2 cells were treated with NF-AM and MG5276F-AM $(6.25,12.5,25$, and $50 \mu \mathrm{g} / \mathrm{mL})$ for $24 \mathrm{~h}$. (B) Viability of $\mathrm{H}_{2} \mathrm{O}_{2}$-induced HepG2 cells pre-treated with or without NF-AM and MG5276F-AM $(6.25,12.5,25$, and $50 \mu \mathrm{g} / \mathrm{mL})$. Values are presented as mean $\pm \operatorname{SEM}(n=3)$. Means with the different letters indicate significantly differences determined by Duncan's multiple range tests $(p<0.05)$.

Oxidative stress factors, including $\mathrm{H}_{2} \mathrm{O}_{2}$, cause cytotoxicity by damaging cells and DNA [1]. It has been reported that $1 \mathrm{mM} \mathrm{H}_{2} \mathrm{O}_{2}$ increases cell toxicity and ROS production in HepG2 [29,30]. These reports are consistent with our study showing that $\mathrm{H}_{2} \mathrm{O}_{2}$ causes toxicity at a concentration of $1 \mathrm{mM}$. In addition, fermentation of grape skin can protect HepG2 cells from $\mathrm{H}_{2} \mathrm{O}_{2}$ damage via bioconversion to produce compounds with antioxidant activity [31]. Similarly, in our study, MG4276F-AM showed higher cell protection against oxidative damage than NF-AM because of bioconversion through fermentation. 


\subsection{Effect of NF-AM and MG5276F-AM on Antioxidant Enzymes in $\mathrm{H}_{2} \mathrm{O}_{2}$-Induced HepG2 Cells}

To confirm that fermenting $A$. membranaceus can enhance the activity of intracellular antioxidant enzymes, mRNA expression levels of CAT, SOD, and GPx were measured in $\mathrm{H}_{2} \mathrm{O}_{2}$-induced HepG2 cells (Figure 3). When HepG2 cells were treated with only $1 \mathrm{mM}$ $\mathrm{H}_{2} \mathrm{O}_{2}$, the mRNA expression levels of CAT, SOD, and GPx were significantly reduced. However, NF-AM and MG5276F-AM increased in a concentration-dependent manner the mRNA expression levels of CAT, SOD, and GPx in $\mathrm{H}_{2} \mathrm{O}_{2}$-induced HepG2 cells; in particular, MG5276F-AM ( $50 \mu \mathrm{g} / \mathrm{mL})$ restored the mRNA expression levels of CAT, SOD, and GPx in the control.

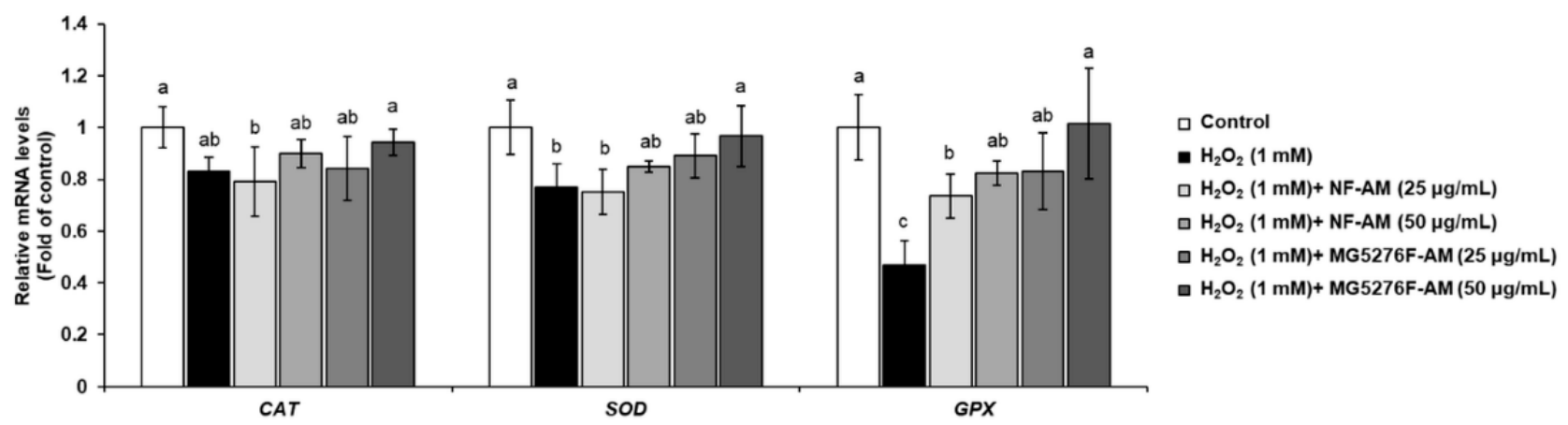

Figure 3. Antioxidant enzyme levels of CAT, SOD, and GPx in $\mathrm{H}_{2} \mathrm{O}_{2}$-induced HepG2 cells treated with NF-AM and MG5276F-AM (25 and $50 \mu \mathrm{g} / \mathrm{mL})$. Values are presented as mean \pm SEM $(n=3)$. Means with the different letters indicate significantly differences determined by Duncan's multiple range tests $(p<0.05)$.

CAT, SOD, and GPx are known to protect cells from oxidative damage caused by $\mathrm{H}_{2} \mathrm{O}_{2}$ by indirectly and/or directly reducing free radicals [5]. Calycosin, an isoflavonoid mainly found in the roots of A. membranaceus, elevates intracellular antioxidant enzymes by binding to the cell membrane [32]. In addition, formononetin, which is the main isoflavonoid of $A$. membranaceus, has a protective effect against $\mathrm{H}_{2} \mathrm{O}_{2}$-induced oxidative damage in HepG2 cells [33]. Thus, it was confirmed that the cytoprotective effect of MG5276F-AM on $\mathrm{H}_{2} \mathrm{O}_{2}$-treated HepG2 cells was due to the reduction of oxidative damage by isoflavonoid conferred by fermentation, which increased the mRNA expression level of antioxidant enzymes. In our previously study, MG5276F-AM decreased NO production and inflammatory related mRNA expression, iNOS, and COX-2 [15]. NO produced by the expression of iNOS and COX-2 is the reactive nitrogen species that causes oxidative stress together with ROS [34]. Thus, reduction of factors associated with inflammation by MG5276F-AM participate in expression of antioxidant enzymes that defend against oxidative stress.

\subsection{Effect of NF-AM and MG5276F-AM on AST and ALT in t-BHP-Injected Mice}

AST and ALT induce toxicity in the liver by causing oxidative stress [35]. To determine the effect of MG5276F-AM on oxidative damage by $t$-BHP injection, serum AST and ALT levels were measured (Figure 4). $t$-BHP injection is ultimately toxic because of the response to factors related to oxidative stress [36]. Thus, an increase in serum AST and ALT levels compared to the non-injection group indicated that oxidative stress in the liver was normally induced by $t$-BHP [35]. The serum AST and ALT levels were increased in the $t$-BHP-injected group, by 2.11- and 2.22-fold, respectively, compared to the non-injection group. In the MG5276F-AM group, both serum AST and ALT levels were significantly reduced at all concentrations. 
(A)

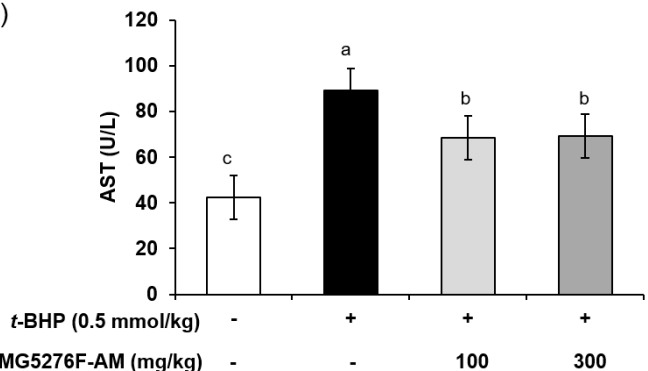

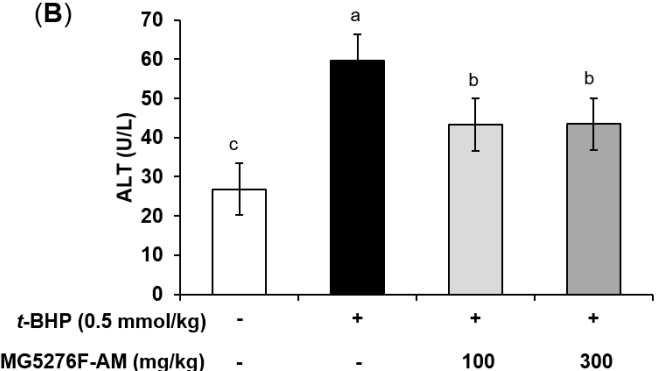

Figure 4. The serum AST (A), and ALT (B) levels of MG5276F-AM (100 and $300 \mathrm{mg} / \mathrm{kg}$ ) in $t$-BHP injected mice. Values are presented as mean $\pm \operatorname{SEM}(n=7)$. Means with the different letters indicate significantly differences determined by Duncan's multiple range tests $(p<0.05)$.

\subsection{Effect of NF-AM and MG5276F-AM on Antioxidant Parameters in t-BHP-Injected Mice}

The $t$-BHP-injected animal model is mainly used to observe the antioxidant effects of many compounds and extracts. Lipid peroxidation (MDA levels) and GSH in serum are used as early-stage biomarkers of oxidative stress [35]. To confirm the antioxidant effect of MG5276F-AM, MDA and GSH levels were evaluated (Figure 5A,B). Figure 5A shows that MG5276F-AM inhibited MDA levels (0.72-fold of the $t$-BHP-injected group at $300 \mathrm{mg} / \mathrm{kg}$ ) as much as the normal group compared to mice injected with $t$-BHP (1.52-fold of noninjection group). With respect to glutathione levels, $t$-BHP-injected mice had 0.92 times the normal control; however, MG5276F-AM slightly increased glutathione levels (Figure 5B). In addition, it was confirmed that CAT, SOD, and GPx were affected by MG5276F-AM, as in vitro (Figure 5C-E). MG5276F-AM restored the levels of CAT and GPx lowered by $t$-BHP injection to the same extent as in the normal group, but no change in SOD levels was observed in any group.

(A)

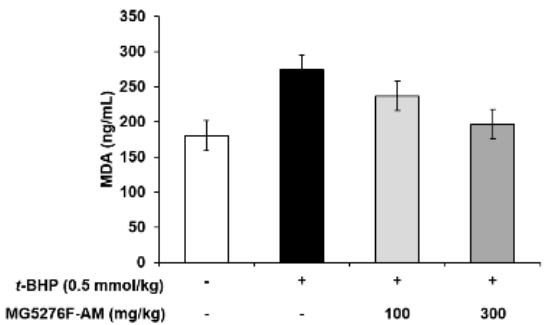

(C)

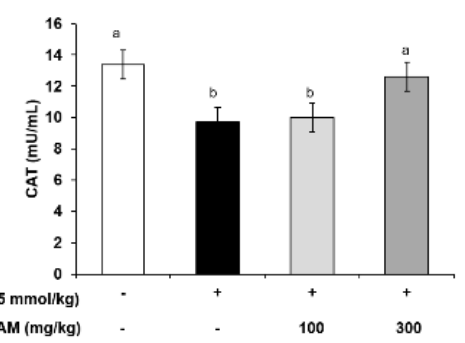

(B)
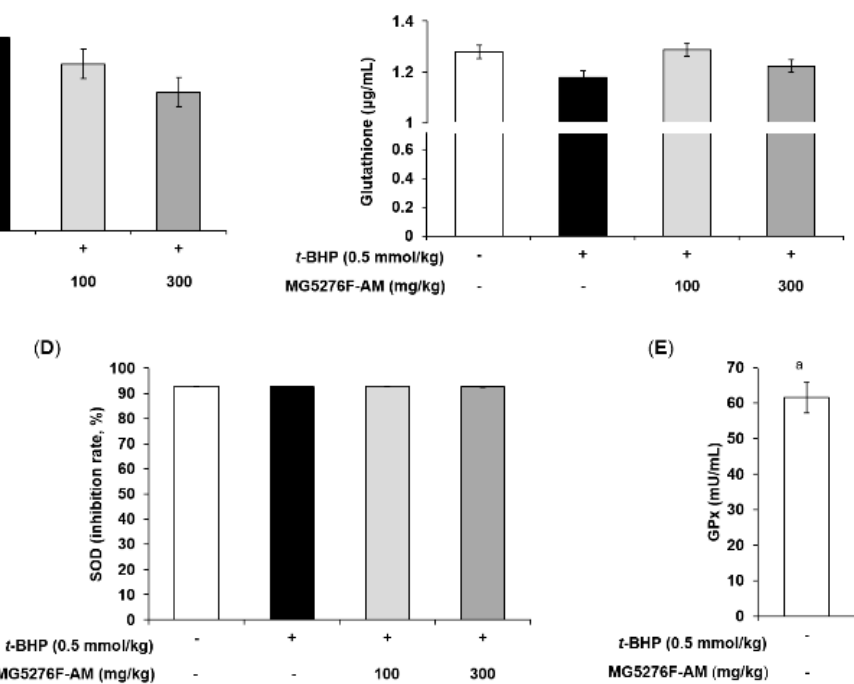

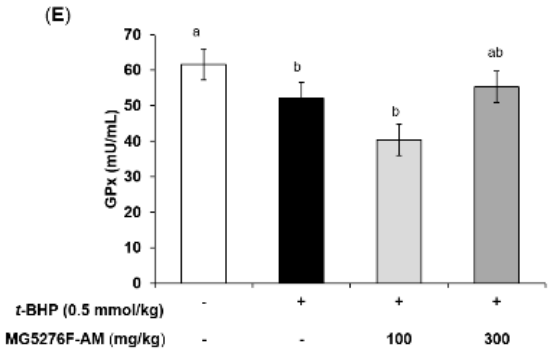

Figure 5. Effect of MG5276F-(100 and $300 \mathrm{mg} / \mathrm{kg}$ ) on (A) MDA, (B) glutathione levels, (C) CAT, (D) SOD, and (E) GPx in $t$-BHP injected mice. Values are presented as mean $\pm \operatorname{SEM}(n=7)$. Means with the different letters indicate significantly differences determined by Duncan's multiple range test $(p<0.05)$. MG5276F-AM, A. membranaceus fermented with L. plantarum MG5276.

t-BHP induces lipid peroxidation through iron-dependent reactions. In addition, $t$-BHP is oxidized to $t$-butoxyl radicals, and endogenous GSH is involved and plays a major role in inducing oxidative stress [36]. It was reported that fermented soybean extract showed antioxidant effects via recovery of lipid peroxidation and glutathione levels in t-BHP injected rats, and increased antioxidant enzymes in HepG2 cells and rats [37]. In 
our study, MG5276F-AM alleviated lipid peroxidation and glutathione levels. Additionally, CAT and GPx were increased by MG5276F-AM as in HepG2 cells. Taken together, MG5276FAM is valuable as a functional food with antioxidant effects in both HepG2 cells and $t$-BHP-injected mouse models induced by oxidative stress, via the increase of aglycone through bioconversion of isoflavonoids by fermentation.

\section{Conclusions}

This study investigated the ability of L. plantarum MG5276, which abundantly produces $\beta$-glucosidase, to enhance the antioxidant activity of $A$. membranaceus by bioconversion of isoflavone glycosides to aglycone. Fermentation using L. plantarum MG5276 of A. membranaceus achieved biological conversion of isoflavonoid glycosides, calycosin- $\mathrm{G}$, and formononetic-G, into aglycones, calycosin, and formononetin. In addition, $A$. membranaceus fermented by L. plantarum MG5276 showed antioxidant efficacy against both $\mathrm{H}_{2} \mathrm{O}_{2}$-induced oxidative stress in HepG2 cells and in animal models injected with $t$-BHP. In conclusion, A. membranaceus fermented by L. plantarum MG5276 can have value as a functional food with enhanced antioxidant activity.

Supplementary Materials: The following are available online at https: / www.mdpi.com/article/ 10.3390 / fermentation8010034/s1, Figure S1: Effect of $\mathrm{H}_{2} \mathrm{O}_{2}$ on HepG2 cells viability.

Author Contributions: Conceptualization, C.-H.K.; methodology, J.Y.L.; validation, J.Y.L. and H.M.P.; formal analysis, J.Y.L. and H.M.P.; investigation, J.Y.L.; resources, C.-H.K.; writing-original draft preparation, J.Y.L.; writing—review and editing, J.Y.L. and C.-H.K.; supervision, C.-H.K. All authors have read and agreed to the published version of the manuscript.

Funding: This research received no external funding.

Institutional Review Board Statement: The animal study protocol was approved by the Institutional Ethics Committee of NDIC (P214057).

Informed Consent Statement: Not applicable.

Data Availability Statement: Not applicable.

Acknowledgments: This research was supported by the Encouragement program for the healthcare natural products industry (Chungcheongbuk-do, Jecheon-si).

Conflicts of Interest: The authors declare no conflict of interest.

\section{References}

1. Young, I.; Woodside, J. Antioxidants in health and disease. J. Clin. Pathol. 2001, 54, 176-186. [CrossRef]

2. Yashin, A.; Yashin, Y.; Xia, X.; Nemzer, B. Antioxidant activity of spices and their impact on human health: A review. Antioxidants 2017, 6, 70. [CrossRef] [PubMed]

3. Chaves, N.; Santiago, A.; Alías, J.C. Quantification of the antioxidant activity of plant extracts: Analysis of sensitivity and hierarchization based on the method used. Antioxidants 2020, 9, 76. [CrossRef] [PubMed]

4. Matés, J.M.; Pérez-Gómez, C.; De Castro, I.N. Antioxidant enzymes and human diseases. Clin. Biochem. 1999, 32, 595-603. [CrossRef]

5. Adwas, A.A.; Elsayed, A.; Azab, A.; Quwaydir, F. Oxidative stress and antioxidant mechanisms in human body. J. Appl. Biotechnol. 2019, 6, 43-47.

6. Kim, J.G.; Dong, X.; Park, S.H.; Bayazid, A.B.; Jeoung, S.A.; Lim, B.O. Bioconversion of black rice and blueberry regulate immunity system through regulation of MAPKs, NF-kB in RAW264. 7 macrophage cells. Food Agr. Immunol. 2021, 32, 471-481. [CrossRef]

7. Czekała, W. Concept of IN-OIL project based on bioconversion of by-products from food processing industry. J. Ecol. Eng. 2017, 18, 180-185. [CrossRef]

8. Eom, S.J.; Kim, K.-T.; Paik, H.-D. Microbial bioconversion of ginsenosides in Panax ginseng and their improved bioactivities. Food Rev. Int. 2018, 34, 698-712. [CrossRef]

9. Lee, N.-K.; Paik, H.-D. Bioconversion using lactic acid bacteria: Ginsenosides, GABA, and phenolic compounds. J. Microbiol. Biotechnol. 2017, 27, 869-877. [CrossRef]

10. Lee, Y.; Oh, J.; Jeong, Y.-S. Lactobacillus plantarum-mediated conversion of flavonoid glycosides into flavonols, quercetin, and kaempferol in Cudrania tricuspidata leaves. Food Sci. Biotechnol. 2015, 24, 1817-1821. [CrossRef] 
11. Jung, J.; Jang, H.J.; Eom, S.J.; Choi, N.S.; Lee, N.-K.; Paik, H.-D. Fermentation of red ginseng extract by the probiotic Lactobacillus plantarum KCCM 11613P: Ginsenoside conversion and antioxidant effects. J. Ginseng Res. 2019, 43, 20-26. [CrossRef]

12. Kim, B.-H.; Jang, J.-O.; Lee, J.-H.; Park, Y.; Kim, J.-G.; Yoon, Y.-C.; Jeong, S.J.; Kwon, G.-S.; Lee, J.-B. Increased anti-oxidative activity and whitening effects of a Saposhnikovia extract following bioconversion fermentation using Lactobacillus plantarum BHN-LAB 33. J. Life Sci. 2019, 29, 1208-1217.

13. Park, J.-Y. Protective Activity of Roasted Astragalus membranaceus against UVB-Induced Damage in Human Dermal Fibroblasts and Artificial Skin Tissues. Master's Thesis, Chungbuk National University, Cheongju, Korea, 2020.

14. Li, Y.; Guo, S.; Zhu, Y.; Yan, H.; Qian, D.-W.; Wang, H.-Q.; Yu, J.-Q.; Duan, J.-A. Comparative analysis of twenty-five compounds in different parts of Astragalus membranaceus var. mongholicus and Astragalus membranaceus by UPLC-MS/MS. J. Pharm. Anal. 2019, 9, 392-399. [CrossRef] [PubMed]

15. Park, H.M.; Lee, J.Y.; Kim, M.Y.; Kang, C.-H.; Hwang, H.S. Anti-oxidative and anti-inflammatory activities of Astragalus membranaceus fermented by Lactiplantibacillus plantarum on LPS-Induced RAW 264.7 cells. Fermentation 2021, 7, 252. [CrossRef]

16. Xu, X.; Li, F.; Zhang, X.; Li, P.; Zhang, X.; Wu, Z.; Li, D. In vitro synergistic antioxidant activity and identification of antioxidant components from Astragalus membranaceus and Paeonia lactiflora. PLoS ONE 2014, 9, e96780. [CrossRef] [PubMed]

17. Zhang, Y.; Hu, G.; Lin, H.C.; Hong, S.J.; Deng, Y.H.; Tang, J.Y.; Seto, S.W.; Kwan, Y.W.; Waye, M.M.Y.; Wang, Y.T. Radix astragali extract promotes angiogenesis involving vascular endothelial growth factor receptor-related phosphatidylinositol 3-kinase/Akt-dependent pathway in human endothelial cells. Phytother. Res 2009, 23, 1205-1213. [CrossRef] [PubMed]

18. Van Meerloo, J.; Kaspers, G.J.; Cloos, J. Cell sensitivity assays: The MTT assay. In Cancer Cell Culture; Humana Press: Totowa, NJ, USA, 2011; pp. 237-245.

19. Livak, K.J.; Schmittgen, T.D. Analysis of relative gene expression data using real-time quantitative PCR and the $2^{-\Delta \Delta C T}$ method. Methods 2001, 25, 402-408. [CrossRef] [PubMed]

20. Kim, D.H.; Kim, M.; Oh, S.B.; Lee, K.M.; Kim, S.M.; Nho, C.W.; Yoon, W.B.; Kang, K.; Pan, C.H. The protective effect of antioxidant enriched fractions from colored potatoes against hepatotoxic oxidative stress in cultured hepatocytes and mice. J. Food Biochem. 2017, 41, e12315. [CrossRef]

21. Part 1: Validation of analytical procedures: Text and methodology. In Ich Harmonised Tripartite Guideline; Somatek Inc.: San Diego, CA, USA, 2005; p. 5.

22. Toda, S.; Shirataki, Y. Inhibitory effects of isoflavones in roots of Astragalus membranaceus Bunge (Astragali Radix) on lipid peroxidation by reactive oxygen species. Phytother. Res. 1998, 12, 59-61. [CrossRef]

23. Ávila, M.; Hidalgo, M.; Sánchez-Moreno, C.; Pelaez, C.; Requena, T.; de Pascual-Teresa, S. Bioconversion of anthocyanin glycosides by Bifidobacteria and Lactobacillus. Food Res. Int. 2009, 42, 1453-1461. [CrossRef]

24. Georgieva, R.; Iliev, I.; Haertlé, T.; Chobert, J.-M.; Ivanova, I.; Danova, S. Technological properties of candidate probiotic Lactobacillus plantarum strains. Int. Dairy J. 2009, 19, 696-702. [CrossRef]

25. Yuksekdag, Z.; Cinar Acar, B.; Aslim, B.; Tukenmez, U. $\beta$-Glucosidase activity and bioconversion of isoflavone glycosides to aglycones by potential probiotic bacteria. Int. J. Food Prop. 2017, 20, S2878-S2886. [CrossRef]

26. Rekha, C.; Vijayalakshmi, G. Bioconversion of isoflavone glycosides to aglycones, mineral bioavailability and vitamin B complex in fermented soymilk by probiotic bacteria and yeast. J. Appl. Microbiol. 2010, 109, 1198-1208. [CrossRef] [PubMed]

27. Kim, B.-H.; Jang, J.-O.; Lee, J.-H.; Park, Y.-E.; Kim, J.-G.; Yoon, Y.-C.; Jeong, S.J.; Kwon, G.-S.; Lee, J.-B. Bioconversion of glycosides isoflavones to aglycone isoflavones by Lactobacillus rhamnosus BHN-LAB 76 under anaerobic conditions. Korean J. Food Preserv. 2019, 26, 148-156. [CrossRef]

28. Pan, H.; Fang, C.; Zhou, T.; Wang, Q.; Chen, J. Accumulation of calycosin and its 7-O- $\beta$-D-glucoside and related gene expression in seedlings of Astragalus membranaceus Bge. var. mongholicus (Bge.) Hsiao induced by low temperature stress. Plant Cell Rep. 2007, 26, 1111-1120. [CrossRef] [PubMed]

29. Bak, M.-J.; Jeong, W.-S.; Kim, K.-B. Detoxifying effect of fermented black ginseng on $\mathrm{H}_{2} \mathrm{O}_{2}$-induced oxidative stress in HepG2 cells. Int. J. Mol. Med. 2014, 34, 1516-1522. [CrossRef] [PubMed]

30. Ryu, H.M.; Kim, Y.J.; Oh, E.J.; Oh, S.H.; Choi, J.Y.; Cho, J.H.; Kim, C.D.; Park, S.H.; Kim, Y.L. Hypoxanthine induces cholesterol accumulation and incites atherosclerosis in apolipoprotein E-deficient mice and cells. J. Cell Mol. Med. 2016, 20, 2160-2172. [CrossRef]

31. Liu, J.; Tan, F.; Liu, X.; Yi, R.; Zhao, X. Grape skin fermentation by Lactobacillus fermentum CQPC04 has anti-oxidative effects on human embryonic kidney cells and apoptosis-promoting effects on human hepatoma cells. RSC Adv. 2020, 10, 4607-4620. [CrossRef]

32. Gao, J.; Liu, Z.J.; Chen, T.; Zhao, D. Pharmaceutical properties of calycosin, the major bioactive isoflavonoid in the dry root extract of Radix astragali. Pharm. Biol. 2014, 52, 1217-1222. [CrossRef]

33. Wang, F.; Zhao, S.; Li, F.; Zhang, B.; Qu, Y.; Sun, T.; Luo, T.; Li, D. Investigation of antioxidant interactions between Radix Astragali and Cimicifuga foetida and identification of synergistic antioxidant compounds. PLoS ONE 2014, 9, e87221. [CrossRef]

34. Sekhar, S.; Sampath-Kumara, K.K.; Niranjana, S.R.; Prakash, H.S. Attenuation of reactive oxygen/nitrogen species with suppression of inducible nitric oxide synthase expression in RAW 264.7 macrophages by bark extract of Buchanania lanzan. Pharmacogn. Mag. 2015, 11, 283. [PubMed]

35. Oh, J.M.; Jung, Y.S.; Jeon, B.S.; Yoon, B.I.; Lee, K.S.; Kim, B.H.; Oh, S.J.; Kim, S.K. Evaluation of hepatotoxicity and oxidative stress in rats treated with tert-butyl hydroperoxide. Food Chem. Toxicol. 2012, 50, 1215-1221. [CrossRef] [PubMed] 
36. Martín, C.; Martínez, R.; Navarro, R.; Ruiz-Sanz, J.I.; Lacort, M.; Ruiz-Larrea, M.B. tert-Butyl hydroperoxide-induced lipid signaling in hepatocytes: Involvement of glutathione and free radicals. Biochem. Pharmacol. 2001, 62, 705-712. [CrossRef]

37. Kim, E.Y.; Hong, K.-B.; Suh, H.J.; Choi, H.-S. Protective effects of germinated and fermented soybean extract against tert-butyl hydroperoxide-induced hepatotoxicity in HepG2 cells and in rats. Food Funct. 2015, 6, 3512-3521. [CrossRef] 